\title{
ALTERAÇÕES QUÍMICAS DO SOLO APÓS APLICAÇÃO DE BIOSSÓLIDOS DE ESTAÇÃO DE TRATAMENTO DE EFLUENTES DE FÁBRICA DE PAPEL RECICLADO
}

\author{
Epitágoras Rodson Oliveira Costa ${ }^{1}$, Nivaldo Eduardo Rizzi ${ }^{2}$, Helton Damin da Silva ${ }^{3}$, \\ Shizuo Maeda ${ }^{4}$, Osmir José Lavaroni ${ }^{5}$ \\ ${ }^{1}$ Eng. Agrônomo, M.Sc., Volta Grande Reflorestamento, Rio Negrinho, SC, Brasil - epitagorascosta@uol.com.br \\ ${ }^{2}$ Eng. Florestal, Dr., Depto. de Engenharia e Tecnologia Florestal, UFPR, Curitiba, PR, Brasil - niva@ufpr.br \\ ${ }^{3}$ Eng. Florestal, Dr., EMBRAPA Florestas, Colombo, Pr, Brasil - helton@cnpf.embrapa.br \\ ${ }^{4}$ Eng. Agrônomo, Dr., EMBRAPA Florestas, Colombo, Pr, Brasil - maeda@cnpf.embrapa.br \\ ${ }^{5}$ Estatístico, Dr., EMBRAPA Florestas, Colombo, Pr, Brasil - osmir@ cnpf.embrapa.br \\ Recebido para publicação: 27/01/2008 - Aceito para publicação: 30/07/2008
}

\begin{abstract}
Resumo
O estudo dos efeitos da aplicação de resíduos de fábrica de papel reciclado em solos florestais nas propriedades químicas de dois tipos de solo foi o objetivo principal deste trabalho. A utilização de resíduos, mesmo com baixa quantidade de nutrientes, é defendida por vários autores, principalmente visando conciliar as necessidades nutricionais com os processos de ciclagem de nutrientes para se manter a produtividade dos plantios florestais. Utilizando-se de resíduos de fábrica de papel reciclado, foi realizado experimento em casa de vegetação da EMBRAPA, em Colombo (PR). Foram montados, em tubos de PVC, misturas de resíduos em dois tipos de solo, Neossolo Regolítico distrófico húmico e Cambissolo húmico distrófico típico. O delineamento experimental foi realizado em blocos inteiramente casualizados, com três repetições, com dosagens crescentes $\left(0,10,20,40\right.$ e 80 t.ha $\left.{ }^{-1}\right)$. No final do experimento, depois de 147 dias de duração, foi realizada a análise de três camadas de solo: 0-10 cm, 10-20 cm e 20-30 cm. A aplicação dos resíduos de papel reciclado influenciou as propriedades químicas do solo, como o aumento no $\mathrm{pH}$, a diminuição no alumínio trocável, a diminuição da acidez potencial, o aumento nos níveis de cálcio e magnésio, o aumento nas camadas iniciais para o fósforo e o aumento na saturação de bases, sem alteração do conteúdo de sódio e matéria orgânica do solo.

Palavras-chave: Resíduos; papel reciclado; fertilidade do solo; nutrientes; alterações químicas do
\end{abstract} solo.

\begin{abstract}
Chemical alterations in the soil after application of residues from recycled paper factory. The study of effects of the residues from recycled paper factory on forest soils in the chemical properties of two kinds of soil, was the main goal of this work. The residues utilization, even with low quantity of nutrients is defended by several authors, aiming mostly conciliate the nutritional needs with the nutrients cycling process to keep the productivities of the forest plantings. Using the residues from recycled paper factory was accomplished the rehearsal at green house of EMBRAPA, in Colombo (PR). Were mounted PVC pipes with residue mixture and two kinds of soil, Neossolo Regolítico distrófico húmico and Cambissolo húmico distrófico typical. The experiment was accomplished in blocks entirely randomized, with three repetitions, with increasing residues dosages $(0,10,20,40$ and

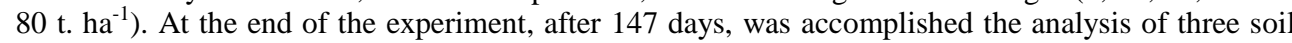
layers: $0-10 \mathrm{~cm} ; 10-20 \mathrm{~cm}$ and $20-30 \mathrm{~cm}$. The residues application of recycled paper influenced the soil chemical properties like $\mathrm{pH}$ increase; decrease in the exchangeable aluminum; decrease of the potential acidity; increase in the calcium and magnesium levels; increase in the initial layers for the phosphorus; increase in the saturation bases; without alteration of sodium content and of the organic matter of the soil.

Keywords: Residues; recycled paper; soil fertility; nutrients; chemical alterations of soil.
\end{abstract}




\section{INTRODUÇÃO}

A produção de papel é geradora de resíduos. Os constantes aumentos na demanda da produção implicam a geração diária de grande quantidade de resíduos, em função dos diferentes processos tecnológicos e da qualidade das aparas de papel, constituindo uma preocupação ambiental (MORO; GONÇALVES, 1995).

O lodo da Estação de Tratamento de Efluentes (ETE) tem potencial para uso como fertilizante ou como condicionador de solos. Possui algumas limitações como fertilizante, apresentando alto teor de matéria orgânica e baixos teores de Al, Na e K (NOLASCO et al., 2005), os quais, em solo, alteram a relação $\mathrm{C} / \mathrm{N}$ e são limitantes como fertilizantes, mesmo que com baixos impactos em relação ao $\mathrm{Al}$ e $\mathrm{Na}$. Reissmann (2002) e Belote; Silva (2005) afirmam que, se houver falta de nutrientes no solo, é indicado o fornecimento de fertilizantes ou resíduos urbanos e industriais.

Normalmente, as quantidades de nutrientes nos resíduos são baixas, não substituindo totalmente a adubação mineral (BELOTE; SILVA, 2005). O uso de resíduos industriais conjuntamente com a adubação mineral deverá merecer atenção da pesquisa, respeitando-se os aspectos ambientais (REISSMANN; WISNIEWSKI, 2005).

Nas florestas de Pinus, é importante conciliar os processos de ciclagem, a atividade biológica e a aplicação de fertilizantes e resíduos orgânicos, para se manter a qualidade do sítio e a sustentação da produtividade (REISSMANN; WISNIEWSKI, 2005). O equilíbrio entre a entrada e a saída de nutrientes é condição fundamental para a manutenção da produtividade, principalmente em florestas implantadas em solos pobres (GONÇALVES, 1988).

Esperam-se ganhos significativos na produção de Pinus com a aplicação de resíduos de indústrias de papel e celulose, aumentando a decomposição da serapilheira e melhorando a capacidade de retenção da água no solo (FERREIRA et al., 2004).

Secchi; Casiraghi (2004) experimentaram, em casa de vegetação, doses crescentes de resíduos de fábrica de papel reciclado em mudas de Pinus taeda. Citam a possibilidade de uso do lodo, agregando nutrientes ao solo, como fósforo, potássio, cálcio, magnésio e manganês.

Balbinot Júnior et al. (2006) utilizaram resíduos de fábrica de papel reciclado misturados com calcário dolomítico, com aplicação no solo, em casa de vegetação, para avaliar as modificações nas propriedades químicas do solo. Os resultados mostraram aumento no $\mathrm{pH}$ do solo, aumento na CTC, redução da acidez potencial e aumento na relação de cálcio e magnésio.

Segundo Kinjo et al. (1992), a aplicação de efluentes de fábrica de celulose causa elevação do pH do solo. Efeito também relatado por Costa et al. (2002), com uso de resíduo de papel reciclado influenciando o $\mathrm{pH}$ do solo em dois tipos de solo.

Rodrigues (2004) mostrou os efeitos no solo de resíduo celulósico, aplicado em diferentes dosagens $\left(0,20,40,80\right.$ e 100 t.ha $\left.^{-1}\right)$ em florestas de Pinus taeda. A aplicação do resíduo celulósico resultou no aumento da matéria orgânica, das bases trocáveis, da saturação de bases e da capacidade de troca catiônica, bem como redução dos níveis de alumínio.

Andrade et al. (2003) relatam a resposta positiva da aplicação de resíduo de celulose em floresta de Eucalyptus aos 6 anos de idade, com maiores produções de madeira em relação à testemunha entre 20 a $40 \%$. A adição de fósforo ao resíduo celulósico proporcionou ganhos entre 52 e $92 \%$.

$\mathrm{O}$ uso de resíduos favorece e acelera a decomposição da serapilheira, influenciando na ciclagem dos nutrientes, disponibilizando nutrientes para as árvores e aumentando a capacidade de retenção da água (BELOTE et al., 1998).

O objetivo deste artigo foi avaliar, em diferentes taxas de aplicação, a influência dos resíduos da ETE de fábrica de papel reciclado nas características químicas de dois tipos de solos.

\section{MATERIAL E MÉTODOS}

O experimento foi realizado em casa de vegetação do Centro Nacional de Pesquisa de Florestas (CNPF) da Empresa Brasileira de Pesquisa Agropecuária (EMBRAPA), em Colombo (PR). Os solos coletados para o experimento foram escolhidos pela maior ocorrência na área da empresa processadora de papel, em povoamentos de Pinus taeda L. no município de Rio Negrinho (SC), em profundidades compatíveis com o experimento. 
Os resíduos utilizados foram coletados na fábrica de papel higiênico da Cia. Volta Grande de Papel (CVG), em Rio Negrinho. O resíduo da estação de tratamento de efluentes da fábrica apresentou 8,6 de $\mathrm{pH}, 42,9 \%$ de matéria orgânica e 55,5\% de cinzas (COSTA, 2007).

Foram montados vasos com resíduo originário da centrifugação do lodo da estação de tratamento, misturados em dois tipos de solos, Neossolo Regolítico distrófico húmico e Cambissolo húmico distrófico típico. Os vasos, envoltos em tubo de PVC, foram colocados em uma mesa a 1,20 metros do solo (Figura 1). O delineamento experimental foi o inteiramente casualizado, com 3 repetições, para 2 tipos de solo e 5 tratamentos $(0,10,20,40,80$ t/ha) com dosagens de resíduos.

O ensaio na casa de vegetação foi realizado de janeiro a maio de 2006, com duração de 147 dias. Os solos nos vasos foram mantidos úmidos durante todo o experimento, em capacidade de campo, com irrigação periódica. No final do experimento, foram analisadas as três camadas de solo dos vasos: 0-10 $\mathrm{cm}, 10-20 \mathrm{~cm}$ e $20-30 \mathrm{~cm}$. As análises químicas do solo foram executadas no laboratório de solos da Empresa Brasileira de Pesquisa Agropecuária (EMBRAPA), em Colombo (PR).

Os efeitos relativos às camadas do solo nas diferentes profundidades foram submetidos a contrastes ortogonais do teste F (MONTGOMERY, 1991). Os contrastes foram camada 1 versus camada 2 e camada 3 e camada 2 versus camada 3 (STELL; TORRIE, 1981).
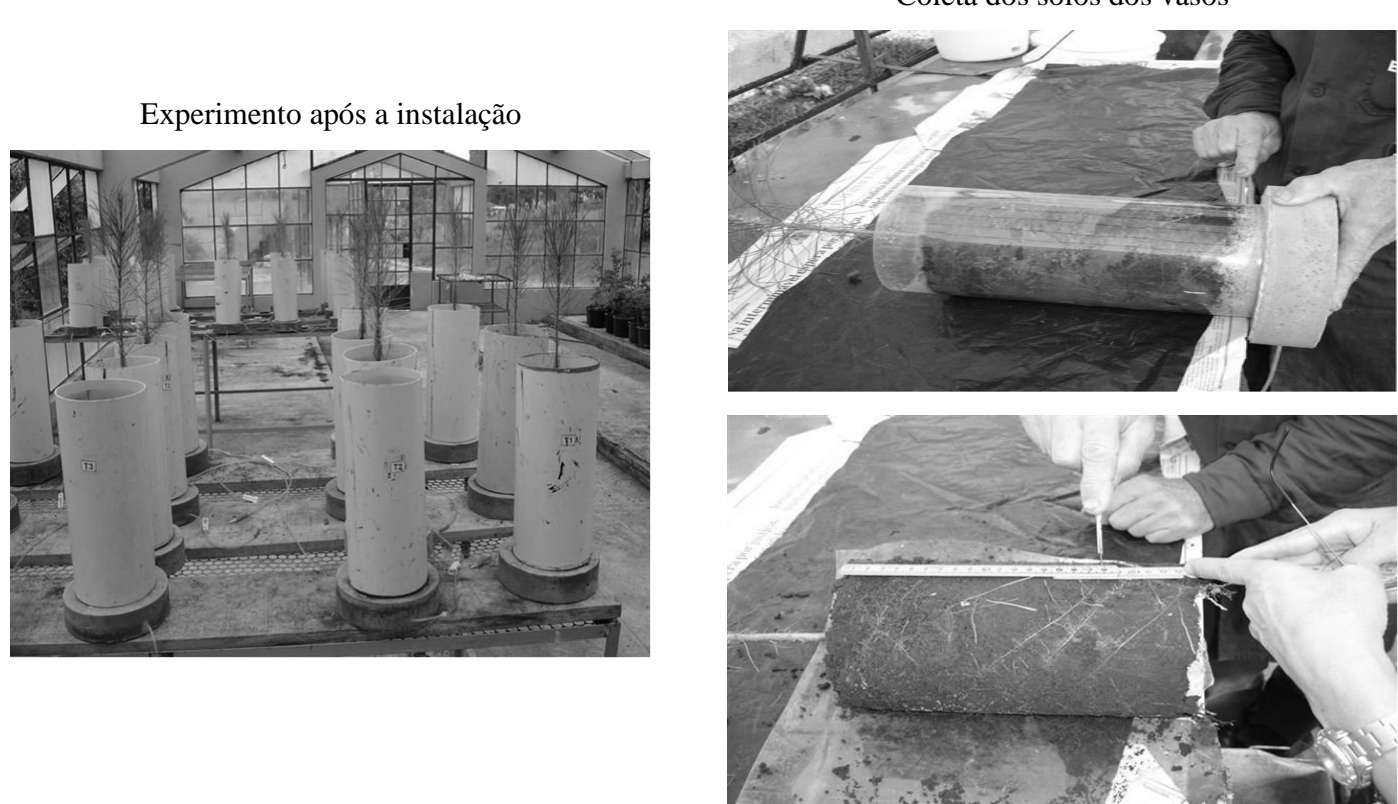

Figura 1. Experimento com resíduos de fábrica de papel reciclado em dois tipos de solo.

Figure 1. Experiment with paper factory residues recycled in two kinds of soil.

\section{RESULTADOS E DISCUSSÃO}

Nas tabelas 1 e 2 constam os resultados das análises químicas dos solos Neossolo Regolítico distrófico húmico e Cambissolo húmico distrófico, respectivamente, conforme a profundidade analisada, após a aplicação de resíduos.

\section{Acidez potencial e alumínio}

Apesar do curto período do experimento, houve uma modificação significativa do $\mathrm{pH}$. As dosagens máximas aplicadas ( $80 \mathrm{t} / \mathrm{ha}$ ), em ambos os solos, proporcionaram os maiores aumentos no $\mathrm{pH}$, em comparação à testemunha (Figura 2). 
Tabela 1. Análise química de Neossolo Regolítico distrófico húmico, com plantio de Pinus taeda L., aos 147 dias de ensaio, com cinco tratamentos com resíduos.

Table 1. Chemical analysis of Neossolo Regolítico distrófico húmico, with Pinus taeda L. planting, at 147 days of experiment, with five treatments with residues.

\begin{tabular}{|c|c|c|c|c|c|c|c|c|c|c|c|c|}
\hline \multirow{2}{*}{$\begin{array}{l}\text { Trat. } \\
\text { t.ha }^{-1}\end{array}$} & \multirow{2}{*}{$\begin{array}{c}\text { Profund. } \\
\text { cm }\end{array}$} & \multirow{2}{*}{$\begin{array}{c}\mathrm{pH} \\
\mathrm{CaCl}_{2}\end{array}$} & $\mathbf{K}$ & $\mathrm{Ca}$ & Mg & $\mathrm{Ca}+\mathrm{Mg}$ & $\mathrm{Al}$ & H+Al & \multirow{2}{*}{$\begin{array}{c}\mathrm{C} \\
\mathrm{g} / \mathbf{d m}^{3}\end{array}$} & $\mathbf{P}$ & $\mathbf{N a}$ & \multirow{2}{*}{ V\% } \\
\hline & & & \multicolumn{6}{|c|}{$\mathrm{cmol}_{\mathrm{c}} / \mathrm{dm}^{3}$} & & \multicolumn{2}{|c|}{$\mathrm{mg} / \mathrm{dm}^{3}$} & \\
\hline$\overline{0}$ & & 3,96 & 0,09 & 1,27 & 0,53 & 1,80 & 1,96 & 13,59 & 27,22 & 5,77 & 45,33 & 13,52 \\
\hline 10 & & 4,86 & 0,09 & 5,71 & 0,74 & 6,46 & 0,22 & 7,85 & 26,49 & 6,53 & 43,67 & 46,69 \\
\hline 20 & $0-10$ & 5,37 & 0,08 & 8,27 & 0,49 & 8,77 & 0,13 & 5,29 & 22,44 & 9,40 & 33,33 & 63,21 \\
\hline 40 & & 6,29 & 0,09 & 12,27 & 1,00 & 13,28 & 0,00 & 2,77 & 24,16 & 10,37 & 29,00 & 83,33 \\
\hline 80 & & 6,74 & 0,10 & 12,58 & 1,09 & 16,67 & 0,00 & 2,24 & 24,28 & 16,13 & 35,00 & 86,62 \\
\hline 0 & & 3,84 & 0,06 & 0,52 & 0,21 & 0,73 & 2,40 & 14,95 & 26,15 & 3,40 & 28,00 & 5,71 \\
\hline 10 & & 3,99 & 0,04 & 1,01 & 0,51 & 1,52 & 1,83 & 13,38 & 23,34 & 3,27 & 22,00 & 11,12 \\
\hline 20 & $10-20$ & 4,27 & 0,04 & 2,59 & 0,95 & 3,54 & 1,23 & 11,88 & 22,23 & 4,43 & 23,33 & 24,18 \\
\hline 40 & & 5,13 & 0,06 & 6,20 & 1,32 & 7,52 & 0,32 & 7,82 & 21,82 & 4,60 & 23,67 & 50,39 \\
\hline 80 & & 5,41 & 0,05 & 7,65 & 1,23 & 8,88 & 0,12 & 5,46 & 22,88 & 6,67 & 22,00 & 62,55 \\
\hline 0 & & 3,81 & 0,20 & 0,52 & 0,11 & 0,63 & 2,57 & 14,99 & 23,68 & 2,73 & 26,27 & 5,99 \\
\hline 10 & & 3,85 & 0,25 & 0,64 & 0,18 & 0,82 & 2,74 & 14,83 & 23,17 & 2,70 & 23,67 & 7,41 \\
\hline 20 & $20-30$ & 3,88 & 0,32 & 0,70 & 0,43 & 1,13 & 2,35 & 14,44 & 21,58 & 3,80 & 28,67 & 10,11 \\
\hline 40 & & 4,04 & 0,38 & 1,12 & 0,69 & 1,82 & 2,42 & 12,51 & 23,26 & 2,57 & 23,67 & 15,49 \\
\hline 80 & & 3,90 & 0,18 & 1,33 & 1,25 & 2,59 & 2,76 & 10,73 & 19,98 & 3,73 & 19,67 & 21,35 \\
\hline
\end{tabular}

As dosagens crescentes também mostraram diferença estatística significativa para o teste $\mathrm{F}$ (valor $<0,05$ ) para o $\mathrm{pH}$. As maiores dosagens de lodo proporcionaram as maiores elevações no $\mathrm{pH}$, concordando com Glória (1992) e Rodrigues (2004).

Tabela 2. Análise química de Cambissolo húmico Distrófico, com plantio de Pinus taeda L., aos 147 dias de ensaio, com cinco tratamentos com resíduos.

Table 2. Chemical analysis of Cambissolo húmico Distrófico, with Pinus taeda L. planting., at 147 days of experiment, with five treatments with residues.

\begin{tabular}{|c|c|c|c|c|c|c|c|c|c|c|c|c|}
\hline \multirow{2}{*}{$\begin{array}{l}\text { Trat. } \\
\text { t/ha }\end{array}$} & \multirow{2}{*}{$\begin{array}{c}\text { Profund. } \\
\text { cm }\end{array}$} & \multirow{2}{*}{$\underset{\mathrm{CaCl}_{2}}{\mathrm{pH}}$} & $\mathbf{K}$ & $\mathrm{Ca}$ & Mg & $\mathrm{Ca}+\mathrm{Mg}$ & $\mathbf{A l}$ & $\mathrm{H}+\mathrm{Al}$ & \multirow{2}{*}{$\begin{array}{c}\mathrm{C} \\
\mathrm{g} / \mathrm{dm}^{3}\end{array}$} & $\overline{\mathbf{P}}$ & $\mathbf{N a}$ & \multirow{2}{*}{ V\% } \\
\hline & & & \multicolumn{6}{|c|}{$\mathrm{cmol}_{\mathrm{c}} / \mathrm{dm}^{3}$} & & \multicolumn{2}{|c|}{$\mathrm{mg} / \mathrm{dm}^{3}$} & \\
\hline 0 & & 4,07 & 0,14 & 3,70 & 1,72 & 5,42 & 2,64 & 11,86 & 35,71 & 10,17 & 56,67 & 33,09 \\
\hline 10 & & 4,72 & 0,13 & 10,34 & 1,16 & 11,49 & 0,55 & 7,78 & 37,19 & 12,63 & 58,67 & 61,07 \\
\hline 20 & $0-10$ & 5,08 & 0,12 & 12,31 & 1,28 & 13,59 & 0,16 & 5,87 & 36,37 & 8,20 & 50,33 & 70,90 \\
\hline 40 & & 6,43 & 0,14 & 15,7 & 2,57 & 18,26 & 0,00 & 5,81 & 35,93 & 13,13 & 39,00 & 78,79 \\
\hline 80 & & 6,85 & 0,15 & 18,33 & 2,13 & 20,46 & 0,00 & 2,18 & 36,35 & 16,60 & 48,00 & 90,98 \\
\hline 0 & & 3,85 & 0,09 & 1,60 & 0,91 & 2,51 & 3,82 & 12,66 & 33,14 & 6,07 & 31,00 & 17,89 \\
\hline 10 & & 4,18 & 0,08 & 4,35 & 1,26 & 5,61 & 2,45 & 11,18 & 34,87 & 6,60 & 31,67 & 32,92 \\
\hline 20 & $10-20$ & 4,06 & 0,07 & 2,95 & 1,42 & 4,37 & 2,22 & 10,99 & 34,39 & 4,57 & 25,00 & 29,39 \\
\hline 40 & & 4,22 & 0,09 & 2,91 & 1,39 & 4,31 & 1,58 & 7,77 & 33,53 & 5,13 & 27,00 & 42,39 \\
\hline 80 & & 4,40 & 0,09 & 5,75 & 2,25 & 8,00 & 1,21 & 9,68 & 33,05 & 6,70 & 27,33 & 46,06 \\
\hline 0 & & 3,81 & 0,23 & 1,13 & 1,36 & 2,49 & 4,22 & 13,50 & 34,06 & 4,80 & 27,67 & 17,39 \\
\hline 10 & & 3,81 & 0,22 & 1,09 & 0,79 & 1,88 & 3,98 & 13,43 & 33,41 & 5,13 & 27,67 & 14,25 \\
\hline 20 & $20-30$ & 3,89 & 0,30 & 1,37 & 1,02 & 2,39 & 3,20 & 12,44 & 32,79 & 4,23 & 34,33 & 18,87 \\
\hline 40 & & 3,92 & 0,39 & 1,50 & 1,49 & 2,99 & 2,78 & 12,18 & 33,80 & 3,50 & 21,33 & 22,00 \\
\hline 80 & & 4,03 & 0,27 & 2,23 & 1,09 & 3,32 & 3,06 & 11,33 & 33,42 & 2,03 & 9,00 & 24,31 \\
\hline
\end{tabular}

Tomando-se por base a média nas três camadas, com a aplicação de resíduos no Neossolo, o pH alterou-se de forma progressiva, em 4,23, 4,51, 5,15 e 5,35, respectivamente, em dosagens de 10, 20, 40 e 80 t/ha. Para o Cambissolo, o pH alterou-se para 4,23, 4,34, 4,86 e 5,09, para as mesmas dosagens. Comprovaram-se essas variações, apontando diferença para o teste $\mathrm{F}$ (valor $<0,05$ ), para Neossolo e Cambissolo, sendo que ambos apresentaram alterações acentuadas no $\mathrm{pH}$ nas três camadas do solo, com maior diferença na camada superficial $\mathrm{C} 1(0-10 \mathrm{~cm})$. 

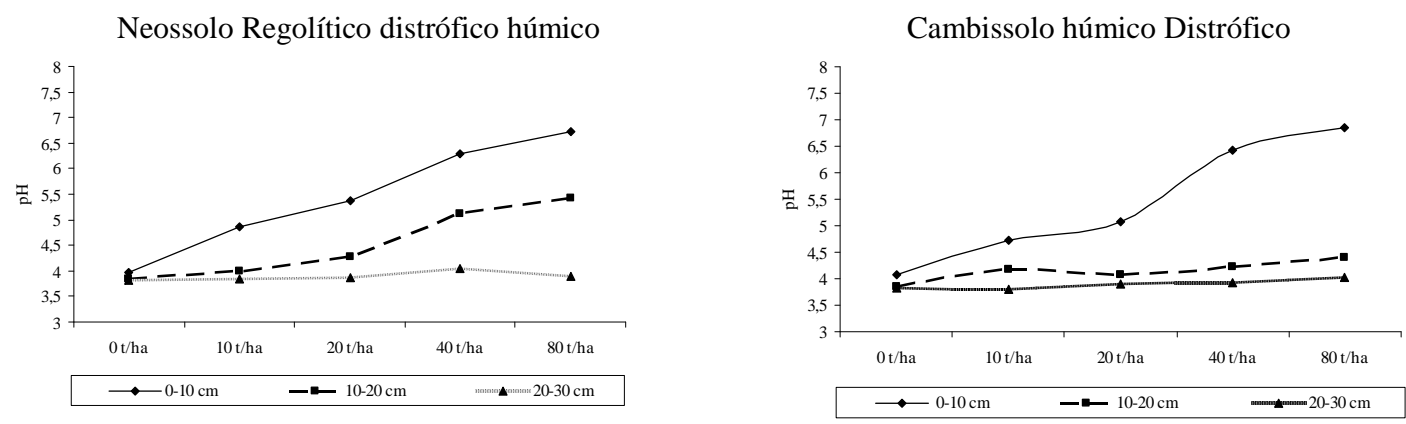

Figura 2. Modificações de pH em dois tipos de solo, após aplicação de resíduos de papel reciclado.

Figure 2. $\mathrm{pH}$ modications in two kinds of soil, after residues application of recycled paper.

Também foram significativos $(\mathrm{F}<0,05)$ os resultados para as camadas do solo onde o $\mathrm{pH}$ é mais alto na camada superficial (0-10), confirmando Kiehl (1985), ao descrever o efeito do uso de resíduos orgânicos no aumento do $\mathrm{pH}$, com maior intensidade nas camadas mais próximas à superfície do solo.

Normalmente, a aplicação de resíduos orgânicos no solo provoca, entre outros efeitos, a diminuição do alumínio trocável no solo (MELO et al., 2002). Os teores de alumínio decresceram de acordo com o aumento das doses de resíduos (Figura 3), efeito confirmado pela análise estatística (valor $\mathrm{p}$ $<0,01)$. As dosagens maiores promoveram diminuição drástica nos teores, chegando a ser nulos nas camadas superiores $(0-10 \mathrm{~cm})$, nas dosagens de 40 e $80 \mathrm{t} / \mathrm{ha}$, nos dois solos.

Neossolo Regolítico distrófico húmico

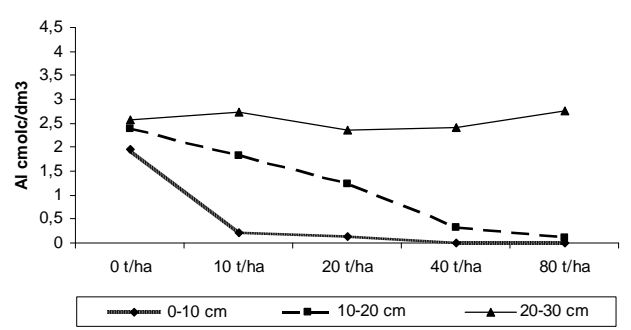

Cambissolo húmico distrófico

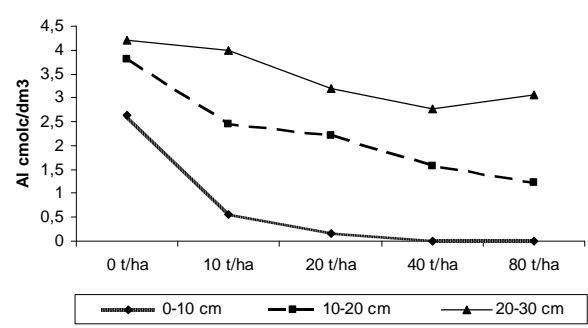

Figura 3. Teores de alumínio em dois tipos de solo, após aplicação de resíduos de papel reciclado. Figure 3. Aluminum levels in two kinds of soil, after residues application of recycled paper.

Isso foi confirmado pela diferença significativa para o teste $\mathrm{F}$ (valor $\mathrm{p}<0,01$ ) para os efeitos de solos. Em ambos os solos, os teores de alumínio cresceram na profundidade e doses aplicadas, o que ficou provado pela diferença estatística, para solos, camadas e doses de aplicação de resíduos.

O incremento nas doses dos resíduos proporcionou diminuição da acidez potencial. Análise estatística apresentou diferença significativa para doses (valor $\mathrm{p}<0,01$ ). Também houve resultados significativos (valor $\mathrm{p}<0,01$ ) para as camadas do solo.

\section{Cálcio e magnésio}

O aumento dos teores de cálcio causado pela aplicação de resíduos, normalmente com altas concentrações, é relatada por diversos autores (MELO et al., 2002; TSUTIYA, 2002; NOLASCO et al., 2005).

Com a aplicação do resíduo da fábrica de papel reciclado, conseguiu-se a elevação nos teores de cálcio (Figura 4) nos dois tipos de solos. Em ambos, as doses crescentes de resíduos proporcionaram incremento dos teores de cálcio, principalmente nas camadas superficiais $(0-10$ e 10-20 cm).

As transformações em ambos os solos, dosagens e camadas, proporcionaram diferenças estatísticas com valor significativo para solos, doses e camadas e todas as suas interações. 

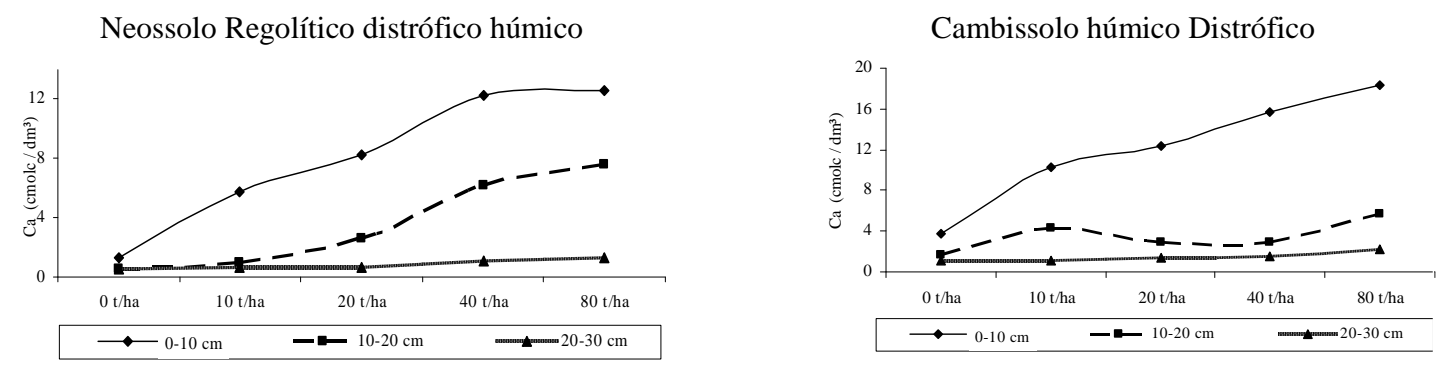

Figura 4. Teores de cálcio em dois tipos de solo, após aplicação de resíduos de papel reciclado. Figure 4. Calcium levels in two kinds of soil, after residues application of recycled paper.

Em geral, o cálcio apresentou-se com maiores teores nas camadas superficiais do solo, diminuindo conforme a profundidade. O mesmo comportamento é relatado por Rodrigues (2004), em tratamento com resíduos celulósicos.

O aumento elevado de teores de nutrientes como o cálcio, contrapondo-se com baixas concentrações de magnésio e potássio, pode trazer problemas na disponibilidade desses elementos (NOLASCO; GUERRINI; BENEDETTI, 2005; RAIJ, 1981).

Os resíduos de papel proporcionaram aumento nos teores de magnésio (Figura 5). Os teores de magnésio são baixos na condição natural (testemunha), crescendo de acordo com o incremento nas doses de resíduos aplicadas, em ambos os solos.
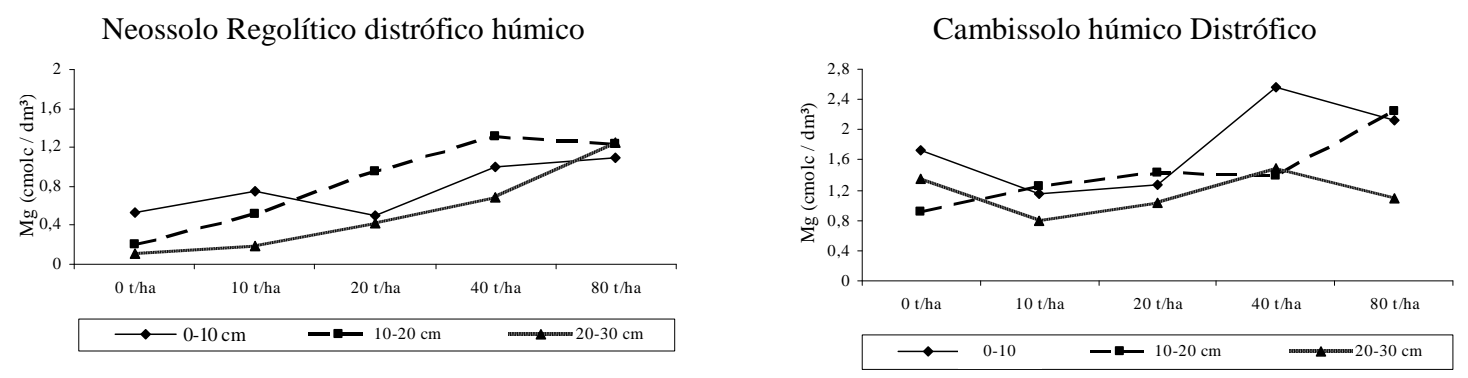

Figura 5. Teores de magnésio em dois tipos de solo, após aplicação de resíduos de papel reciclado. Figure 5. Magnesium levels in two kinds of soil, after residues application of recycled paper.

A análise estatística apresentou resultados significativos para solos e doses (valor $\mathrm{p}<0,01$ ). No estudo das camadas do solo, observou-se que a distribuição do magnésio entre as diferentes profundidades sofreu oscilações, conforme o solo e a profundidade considerada. Essa tendência também foi observada em tratamentos de resíduos celulósicos por Rodrigues (2004). A análise estatística foi significativa para camadas (valor $\mathrm{p}<0,01$ ), porém sem significância nas diversas outras interações entre solos, doses e camadas.

\section{Matéria orgânica}

Normalmente, espera-se aumento no teor de matéria orgânica com a aplicação de resíduos orgânicos no solo (MELO et al., 2002; KIEHL, 1985), fato não comprovado neste experimento, no qual a aplicação de resíduos não implicou o aumento dos teores da matéria orgânica.

No Neossolo, os teores de matéria orgânica na testemunha são médios, em todas as profundidades. A adição de resíduos de papel, em todos os tratamentos, manteve esse teor médio. Com a profundidade no solo, houve tendência de pequena queda (entre 5 a 13\%) nos teores. As dosagens crescentes não resultaram no aumento da matéria orgânica, inclusive com efeito contrário, com decréscimo nas doses de 40 e 80 t/ha. No Cambissolo, foram observados altos teores na testemunha, que praticamente não foram modificados pela adição dos resíduos nas diferentes profundidades no solo. Isso resultou numa diferença estatística significativa para solos, doses e camadas (valor $\mathrm{p}<0,01$ ). 
Diversos autores relatam a complexa relação entre a matéria orgânica e o uso de resíduos, sem as modificações esperadas de aumento nos teores ao longo do perfil. A maioria não apresenta conclusão clara sobre o assunto, atribuindo-se, em alguns casos, ao aumento da atividade microbiana e à baixa relação $\mathrm{C} / \mathrm{N}$ dos resíduos, que, em combinação com a disponibilidade de nutrientes, causou intensificação da atividade microbiana nesse resíduo e no solo, acelerando a taxa de decomposição da matéria orgânica, mecanismo conhecido como "efeito priming" (GUEDES et al., 2006). Também ocorrem dificuldades de reação dos solos tropicais, de promover aumentos significativos nos teores de matéria orgânica em curto espaço de tempo. Tauk (1990) sugere mais estudos sobre biodegradação, em que normalmente a complexidade física e química dos resíduos orgânicos desfavorece a ocorrência de um processo de degradação biologicamente simples, que ocorre no solo.

\section{Potássio e fósforo}

Normalmente, os biossólidos não são boas fontes para o suprimento de potássio (PAGLIA, 2004; NOLASCO et al., 2005). Embora se tenha verificado algum acréscimo após a aplicação de resíduos nos solos, os teores continuaram muito baixos, em todas as dosagens e profundidades (Figura 6). Resultado idêntico encontrou Rodrigues (2004), avaliando tratamentos com resíduo celulósico.
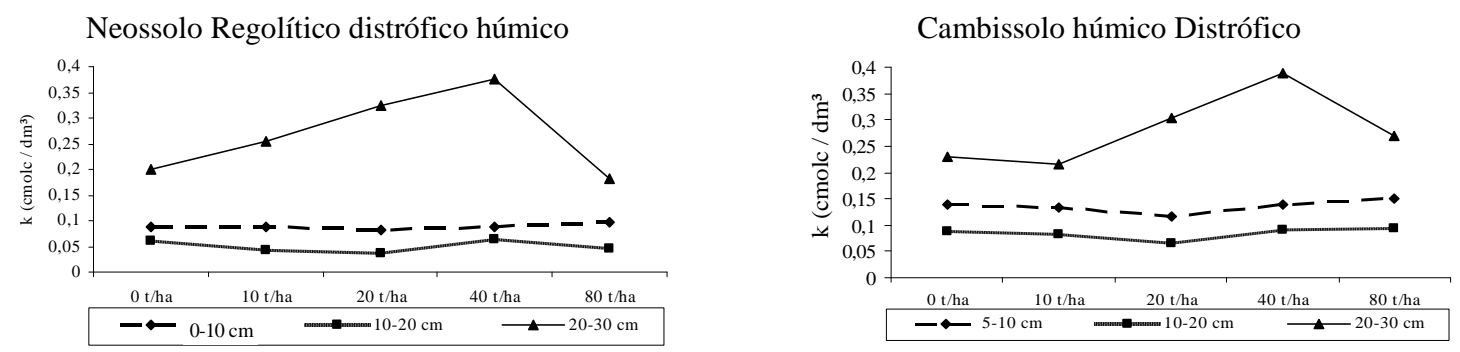

Figura 6. Teores de potássio em dois tipos de solo, após aplicação de resíduos de papel reciclado.

Figure 6. Potassium levels in two kinds of soil, after residues application of recycled paper.

O tratamento testemunha $\left(0,06\right.$ a $\left.0,23 \mathrm{~g} / \mathrm{dm}^{3}\right)$ mostrou teor muito baixo (COMISSÃO DE QUÍMICA E FERTILIDADE DO SOLO - RS/SC, 2004). A aplicação de resíduos nos dois solos resultou em teores muito semelhantes, com pequena diferença (menor) no Neossolo em relação ao Cambissolo.

Nas camadas iniciais do solo $(0-10 \mathrm{~cm})$ ocorreu pouca alteração nos teores de potássio, comparando-se com a testemunha. A concentração foi maior na camada inferior (20-30 cm), mostrado pelo contraste entre as camadas $\mathrm{C} 2$ e $\mathrm{C} 3$ com valor significativo (valor $\mathrm{p}<0,01$ ), para ambos os solos.

No uso desse tipo de resíduo como fertilizante, será indispensável uma suplementação com outras fontes de potássio.

Devem-se citar ainda as possíveis perdas de potássio por lixiviação, causada pela água de irrigação nos vasos do experimento. Também a absorção maior de potássio é dependente de concentrações relativamente baixas do cálcio (MELO et al., 2002; MALAVOLTA, 1981). Neste estudo, os maiores teores de cálcio ocorreram nas camadas superficiais do solo, diminuindo conforme a profundidade no solo. Já o potássio realizou o caminho inverso, acumulando-se nas camadas inferiores do solo.

A adição de resíduo proporcionou ganhos nos teores de fósforo no Neossolo e no Cambissolo (Figura 7). Nesse último com maior intensidade, resultando em diferença estatística para solos com $1 \%$ de probabilidade.

As doses crescentes proporcionaram aumento nos teores, principalmente na camada $\mathrm{C} 1(0-10$ $\mathrm{cm}$ ), superando $16,00 \mathrm{mg} / \mathrm{dm}^{3}$, em ambos os solos, na dose de $80 \mathrm{t} / \mathrm{ha}$, muito superior à testemunha (com 5,76 no Neossolo e $10,17 \mathrm{mg} / \mathrm{dm}^{3}$ no Cambissolo). Isso contribuiu para o valor significativo alcançado (valor $\mathrm{p}<0,01$ ) para as doses de resíduos e também para a interação dos solos com as doses.

Para o Neossolo, a testemunha apresentou baixo teor de fósforo. Com a adição de resíduo, os ganhos foram significativos, principalmente nas camadas iniciais $(0-10 \mathrm{~cm})$, com teores altos a partir de 20 e $40 \mathrm{t} / \mathrm{ha}$ (respectivamente, 9,40 e $10,36 \mathrm{mg} / \mathrm{dm}^{3}$ ) e continuando a crescer na dose com $80 \mathrm{t} / \mathrm{ha}(>16,13$ $\left.\mathrm{mg} / \mathrm{dm}^{3}\right)$. No Cambissolo, houve maior impacto nas camadas iniciais $(0-10 \mathrm{~cm})$, com teores altos nas dosagens acima de $40 \mathrm{t} / \mathrm{ha}$. Nas camadas de $10-20 \mathrm{~cm}$, as mudanças não foram tão significativas, e na camada mais profunda $(20-30 \mathrm{~cm})$ houve decréscimo conforme o aumento nas dosagens de resíduos. 
Neossolo Regolítico distrófico húmico

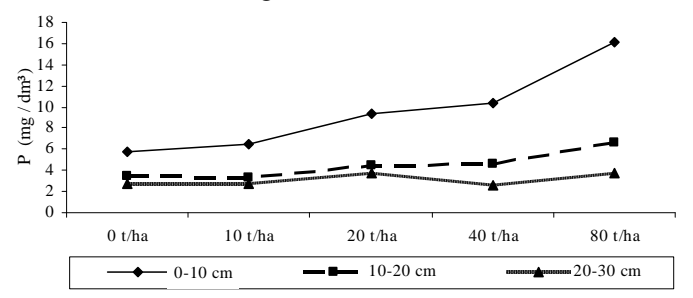

Cambissolo húmico Distrófico

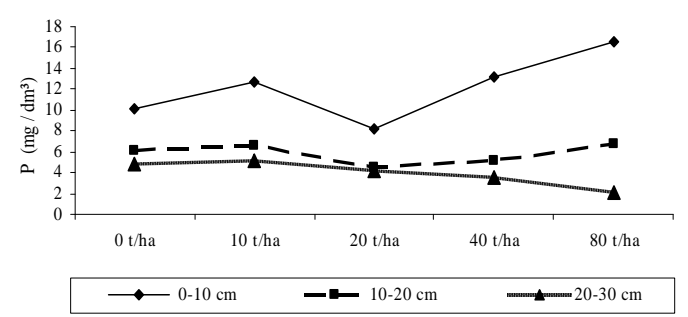

Figura 7. Teores de fósforo em dois tipos de solo, após aplicação de resíduos de papel reciclado. Figure 7. Phosphorus levels in two kinds of soil, after residues application of recycled paper.

Aumentos nas camadas superficiais dos teores de fósforo também foram relatados por Rodrigues (2004), Rezende (2005) e Rocha (2004). Resultado contrário obtiveram Balbinot Júnior et al. (2006) com a aplicação de resíduos de fábrica de papel reciclado, não modificando os teores de fósforo nos tratamentos.

Neste estudo, os resultados são significativos para camadas e para a interação de doses com camadas, com $1 \%$ de probabilidade, e de 5\% para solos e camadas. Quando considerada a interação de solos, doses e camadas, não houve significância estatística.

\section{Saturação em bases (V\%) e sódio (Na)}

Os efeitos dos resíduos foram acentuados em relação à saturação em bases (Figura 8), com aumentos nos dois tipos de solos, dosagens e profundidades. Tanto no Neossolo como no Cambissolo, os resultados foram muito superiores em relação à testemunha, com a análise estatística indicando diferença significativa de $1 \%$.

Neossolo Regolítico distrófico húmico

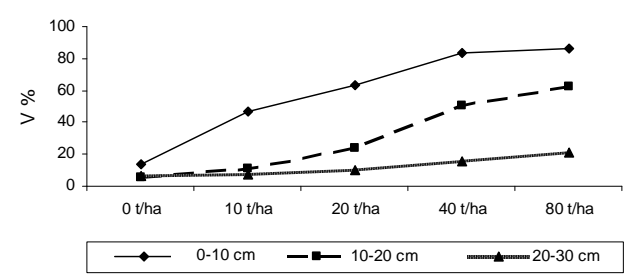

Cambissolo húmico Distrófico

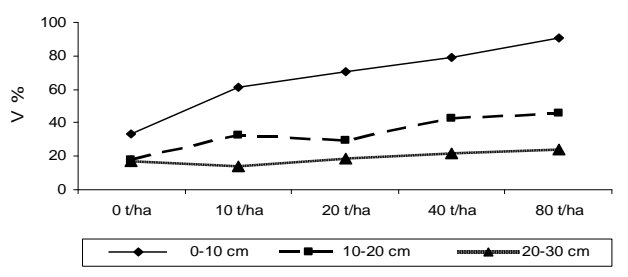

Figura 8. Saturação em bases (V\%), em dois tipos de solo, após aplicação de resíduos de papel reciclado. Figure 8. Base saturations (V\%) in two kinds of soil, after residues application of recycled paper.

Com relação às dosagens, estas proporcionaram ganhos significativos nos percentuais de saturação em bases (V\%). Nas camadas do solo, em ambos os solos, houve maiores diferenças em relação à testemunha na camada $\mathrm{C} 1(0-10 \mathrm{~cm})$. Na camada seguinte $\mathrm{C} 2(10-20 \mathrm{~cm})$, em geral, houve aumento nos percentuais, com maior incremento no Neossolo. Na camada inferior C3 $(20-30 \mathrm{~cm})$, os aumentos foram maiores no Neossolo.

Bellote et al. (1998) citam os efeitos da aplicação de resíduos na saturação em bases em solos, com maiores alterações nos $10 \mathrm{~cm}$ iniciais, em concordância com os resultados deste trabalho.

O resultado elevado para saturação em bases deve merecer atenção, pois, para o Pinus, a saturação em bases recomendada, segundo Ferreira et al. (2001), fica em torno de 40 a $50 \%$. Em algumas situações pode até ser prejudicial ao Pinus, que se adapta melhor em condições de saturação de bases menores, conforme observou Dedecek (2005).

Os teores de sódio no solo não foram influenciados pela aplicação de resíduos. $\mathrm{O}$ acúmulo de sódio no solo pode trazer problemas para sua estrutura, comprometendo a capacidade de infiltração e aeração. Não se confirmaram as observações sobre as altas concentrações do sódio em resíduos da indústria de papel (BELOTE et al., 1998; REZENDE et al., 2000). Os teores existentes naturalmente no solo, representados pelos tratamentos testemunhas, tiveram redução nos dois tipos de solo, em comparação aos tratamentos com resíduos. 


\section{CONCLUSÕES}

A aplicação de biossólidos de estação de tratamento de efluente de fábrica de papel reciclado promoveu alterações nas propriedades químicas do solo, a saber: a) alterou positivamente o $\mathrm{pH}$ do solo, com maior incremento nas camadas superficiais $(0-10 \mathrm{~cm})$; b) alterou negativamente os níveis de $\mathrm{Al}$ e acidez potencial; c) não se observaram efeitos sobre a matéria orgânica e teores de $\mathrm{Na}$.

De forma geral, a aplicação de biossólidos de tratamento de efluentes da indústria de papel reciclado afetou os teores de nutrientes e a fertilidade do solo, promovendo um acréscimo de $\mathrm{Ca}, \mathrm{Mg}, \mathrm{K}$, $P$ e a saturação de bases.

\section{REFERÊNCIAS}

ANDRADE, G. C.; SILVA, H. D. da; BELLOTE, A. F. J.; FERREIRA, C. A. Efeitos da adubação e da aplicação de resíduo de celulose no crescimento de Eucalyptus dunnii. Boletim de Pesquisa Florestal, Colombo, n. 47, p. 43-54, jul. / dez. 2003.

BALBINOT JUNIOR, A. A.; TORRES, A.N. L.; FONSECA, J. A. da.; TEIXEIRA, J. R.; NESI, C. N. Alteração em características químicas de um solo ácido pela aplicação de calcário e resíduos de reciclagem de papel. Revista de Ciências Agroveterinárias, Lages, v. 5, n. 1, p. 16-25, 2006.

BELOTE, A. F. J.; SILVA, H. D. da. Cultivo do Pinus - Adubação. Sistemas de produção. EMBRAPA. Novembro. 2005. Disponível em: <http://: sistemasdeproducao.cnptia.embrapa.br/FontesHTML>L/Pinus /CultivodoPinus/ 09_adubacao.html>. Acesso em: 10/11/2006.

BELlOTE, A. F. J.; SILVA, H. D. da; FERREIRA, C. A.; ANDRADE, G. C. Resíduos da indústria de celulose em plantios florestais. Boletim de Pesquisa Florestal, Colombo, n. 37, p. 99-106, jul. / dez. 1998.

COMISSÃO DE QUÍMICA E FERTILIDADE DO SOLO. Manual de adubação e de calagem para os estados do Rio Grande do Sul e de Santa Catarina. 10. ed. Porto Alegre: SBCS - Núcleo Regional Sul, 2004. $400 \mathrm{p}$.

COSTA, E. R. O. Alterações químicas no solo e na água de percolação após aplicação de resíduos de fábrica de papel de reciclado em Pinus Taeda L. 138f. Dissertação (Mestrado em Engenharia Florestal) - Setor de Ciências Agrárias, Universidade Federal do Paraná, Curitiba, 2007.

COSTA, A. S. V. da; GALVÃO, E. R.; LOVO, I. C.; FERRARI JUNIOR, M. J.; ALMEIDA, L. L.; BENEVIDES, G. Efeitos do resíduo de celulose nas características dos solos e no desenvolvimento de culturas agrícolas. In: CONGRESSO ANUAL DE CELULOSE E PAPEL, 35. São Paulo. Anais ... São Paulo: $\quad$ ABTCP, 2002. Disponível em: $>$ http://www.celuloseonline.com.br/imagembank/Docs/DocBank/dc/dc008.pdf<. Acesso em: 30/05/2007.

DEDECEK, R. Adequação de Áreas Agrícolas para o Plantio de Pinus taeda. Comunicado Técnico, Colombo, n. 12, 3 p., 2005.

FERREIRA, C. A.; SILVA, H. D. da; BELlOTE, A. F. J.; DEDECEK, R.; ANDRADE, G.C.; FERRARI, M. P. Pesquisas sobre nutrição de Pinus no sul do Brasil. Revista da Madeira, Curitiba, n. 63, ano 14, p. 72-78, ago. 2004. Edição Especial.

GLÓRIA, N. A. da Uso agronômico de resíduos. In: REUNIÃO BRASILEIRA DE FERTILIDADE DO SOLO E NUTRIÇÃO DE PLANTAS, 22, 1992, Piracicaba. Anais... Campinas: Fundação Cargill , 1992. p. 195-212.

GONÇALVES, J. L. M. Propriedades físico-químicas dos solos vs. exigências nutricionais de espécies florestais de rápido crescimento. Circular Técnica, Piracicaba, n. 154, p. 1-12, jan. 1988.

GUEDES, M. C.; ANDRADE, C. A.; POGGIANI, F.; MATTIAZZO, M. E. Propriedades Químicas do Solo e Nutrição do Eucalipto em Função da Aplicação de Lodo de Esgoto. Revista Brasileira de Ciência do Solo, Viçosa, MG, v. 30, n. 2, p. 267-280. 2006.

KIEHL, E. J. Fertilizantes orgânicos. São Paulo: Agronômica Ceres, 1985. 492 p. 
KINJO, TON.; SILVEIRA, R. I.; MARCOS, Z. Z.; ABRAHÃO, L. O. Efeito da aplicação de Efluente de Celulose junto com Fosofogesso na correção da Acidez do Solo. Scientia Florestalis, Piracicaba, n. 49, p. 129-135, 1992.

MALAVOLTA, E. Manual de química agrícola adubos e adubação. 3 ed. São Paulo: Agronômica Ceres, 1981. $596 \mathrm{p}$.

MELO, W. J. de; MARQUES, M. O.; MELO, V. P. de. O uso agrícola do biossólido e as propriedades do solo. In: TSUTIYA, M. TON.; COMPARINI, J. B.; SOBRINHO, P. A.; HESPANHOL, I.; CARVALHO, P. C. TON.; MELFI, A. J. MELO, W. J.; MARQUES, M. O. Biossólidos na agricultura. 2. ed. São Paulo: ABES, 2002. p. 289-359.

MONTGOMERY, D.C. Design and analysis of experiments. 3. ed. New York: J.Wiley, 1991. 649 p.

MORO, L.; GONÇALVES, J. L. M. Efeitos da "Cinza" de biomassa Florestal sobre a produtividade de Povoamentos Puros de Eucalyptus grandis e Avaliação Financeira. IPEF, Piracicaba, n. 48/49, p.18-27, jan./dez. 1995.

NOLASCO, A. M.; GUERRINI, I. A.; BENEDETTI, V. Uso de resíduos urbanos e industriais como fonte de nutrientes e condicionadores de solos florestais. Aspectos nutricionais de plantios de Pinus. In: GONÇALVES, J. L.M.; BENEDETTI, V. Nutrição e fertilização florestal. Piracicaba: IPEF, 2005. p 386-414.

PAGLIA, E. C. Lodo de Esgoto Alcalinizado Associado a Doses de Potássio, na Lixiviação Iônica. 57 f. Dissertação (Mestrado em Agronomia) - Setor de Ciências Agrárias, Universidade Federal do Paraná, Curitiba, 2004.

RAIJ, B. V. Avaliação de fertilidade do solo. Piracicaba: Instituto da Potassa e Fosfato, 1981. 142 p.

REISSMANN, C. B.; WISNIEWSKI, C. Aspectos nutricionais de plantios de Pinus. In: GONÇALVES, J.L.M.; BENEDETTI, V. Nutrição e fertilização florestal. Piracicaba: IPEF, 2005. p. 135-165.

REZENDE, A. A. P.; MATOS, A.TON. de ; SILVA, C. M. . Uso do Efluente da Indústria de Papel e Celulose na Irrigação. Saneamento Ambiental. Viçosa, MG, n. 1, p. 32-40, 2000.

REZENDE, C. I. O. Influência da aplicação do lodo de esgoto (biossólido) sobre a concentração e o estoque de nutrientes na biomassa do sub-bosque, na serapilheira e no solo de um talhão de Eucalyptus grandis. 81 f. Dissertação (Mestrado em Ecologia Aplicada) - Escola Superior de Agricultura "Luiz de Queiroz", Universidade de São Paulo, Piracicaba, 2005.

ROCHA, G. N.; GONCALVES, J. L. M.; MOURA, I. M.. Mudanças da fertilidade do solo e crescimento de um povoamento de Eucalyptus grandis fertilizado com biossólido. Revista brasileira de ciência do solo, Viçosa, MG, v. 28, n. 4, p. 623-639, 2004.

RODRIGUES, C. M. Efeito da Aplicação de resíduos da Indústria de Papel e Celulose nos Atributos Químicos, Físicos e Biológicos do Solo, na Nutrição e Biomassa de Pinus taeda L.. 109 f. Dissertação (Mestrado em Agronomia) - Setor de Ciências Agrárias, Universidade Federal do Paraná, Curitiba, 2004.

SECCHI, G. A. R.; CASIRAGHI, K. F. Resíduo do processo de fabricação de papel reciclado potencial de uso como insumo agrícola e/ou florestal. $53 \mathrm{f}$. Monografia (Graduação em Ciências Biológicas) - Universidade Paranaense, Cascavel, 2004.

STELL, R. G. D.; TORRIE, J. H. Principles and Procedures of Statistics: a Biometrical Approach. New York: Mc-Graw, 1981. 33 p.

TAUK, S. M. Biodegradação de Resíduos Orgânicos no Solo. Revista Brasileira de Geociência, São Paulo, v. 20, n.1-4, p. 299-301. 1990.

TSUTIYA, M. TON. Características de Biossólidos Gerados em Estações de Tratamento de Esgotos. In: TSUTIYA, M. TON.; COMPARINI, J. B.; SOBRINHO, P. A.; HESPANHOL, I.; CARVALHO, P. C.TON.; MELFI, A. J. MELO, W. J.; MARQUES, M. O. Biossólidos na agricultura. 2. ed. São Paulo: ABES, 2002. p. 89-131. 